\title{
Evidence of a configurational structure in Meskwaki
}

\author{
Paul A. Morris*
}

\begin{abstract}
Meskwaki, like many polysynthetic Algonquian languages, is often analyzed as having a non-configurational structure because it exhibits the three core characteristics of non-configurationality: free word order, discontinuous expressions, and null anaphora (Hale 1983). While free surface form word order is attributed to a preverbal discourse-based hierarchy, non-topic/focus NPs are in a post-verbal, nonhierarchical XP structure (Dahlstrom 2013). This paper posits that Meskwaki has an underlying configurational syntactic structure based on novel and prior data showing (1) discontinuous NP ordering restrictions with locality constraints, (2) superiority effects in multiple wh-phrases, and (3) long-distance movement and island effects.
\end{abstract}

Keywords. syntax; Meskwaki; Algonquian languages; non-configurational; configurational languages

1. Introduction. Meskwaki (Fox), a Central Plains Algonquian language (Goddard 1978), is a polysynthetic language. Polysynthetic languages obligatorily mark for both subjects and objects on the verb, which allows for many grammatical processes to be expressed in a single word through morphology (Mahieu and Tersis 2009). Verbal morphology in Meskwaki marks for the grammatical features of person, animacy, obviation, and number of subjects and objects (Dahlstrom 1993). Meskwaki utilizes a proximate/obviative nominal marking system to indicate the more discourse-prominent $3^{\text {rd }}$ person noun; proximate marked nouns are more prominent than obviative marked nouns (Thomason 2003). Proximate/obviative marking also distinguishes plurality and contrasts animate and inanimate nouns.

Like many Algonquian languages, Meskwaki exhibits characteristics of non-configurationality as outlined by Hale (1983): 1) free word order, 2) null anaphora, and 3) discontinuous constituents (i.e., Dahlstrom 1995). Non-configurational languages are characterized into two groups based on their marking system: 1) head-marking (i.e., Nahuatl, Mohawk, Meskwaki) and 2) dependent-marking languages (i.e., Warlpiri, Jiwarli) (Nichols 1986). Since both head-marking and dependent-marking languages show non-configurational characteristics, nonconfigurationality does not imply polysynthesis. Additionally, while many polysynthetic languages demonstrate these non-configurational characteristics, not all do; thus, polysynthesis does not necessarily imply non-configurationality.

Free word order: Since head-marking (or dependent-marking) expresses syntactic relationships, such as subject and object, word order does not express syntactic roles. Thus, elements can appear in any order without affecting the argument structure. Instead, word order often varies as a result of discourse-based information structure (Dahlstrom 1993) (1; examples from Meskwaki):

\footnotetext{
* I would like to thank my primary consultant Preston Duncan for sharing his knowledge and for his never-ending patience, as well as Glendora Mauskemo, Conrad Brown, and Yolanda Pushetonequa. I would also like to thank Alice Davison, Emilie Destuel-Johnson, Leigh Hunnicutt, and Alexis Lee for their suggestions and comments. This work was partially supported by a research grant from the ECGPS Grant Program. Any and all errors are mine alone. Author: Paul A. Morris, The University of Iowa (paul-a-morris@uiowa.edu).
} 

neniw-ani
woman-3SG.PROX see-PST-3SG-3'SG man-3'SG.OBV ${ }^{1}$
a. ihkwew-a
ne.awa-kw-e $\cdot$ ni
SVO
'The woman saw the man'
b. ne·awa-kw-e-ni neniw-ani
see-PST3SG-3'sG
man-3'SG.OBV
'The woman saw the man'
ihkwew-a
VOS

Null anaphora: Since information about argument structure is marked on the verb, overt nouns are not required and are frequently omitted in Meskwaki (2). Overt nouns function as emphasis (focus) or to introduce new information (topic) (Dahlstrom 1995).

$$
\begin{aligned}
& \text { n-e.kanuna-wa.k } i \\
& \text { 1sG-talk-DIR-3PL } \\
& \text { 'I talked to them' }
\end{aligned}
$$

Discontinuous constituents: Lexical constituents of a phrase can be split and appear in different parts of a sentence, allowing unrelated elements to intervene between the phrasal constituents (3) (Dahlstrom 2013). In Meskwaki, discontinuous nouns generally take one of two forms: 1) with the head noun fronted and a relative clause final, usually split across a verb, or 2) with a modifier (demonstrative pronouns, quantifiers, adjectives) fronted and the rest of the noun clause final (Dahlstrom 2013):

$$
\begin{array}{llll}
\text { Eh=wikiwa-dgen tchaki } & \text { kwihiki } & \text { neniw-aki } \\
\text { So=home-towards all } & \text { go-PST-3PL } & \text { man-3PL } \\
\text { 'All of the men went home' } & &
\end{array}
$$

As with many non-configurational languages, word order in Meskwaki is heavily influenced by discourse factors (Dahlstrom 1993). Word order, along with proximate/obviative marking, indicates the information structure of a sentence. To the left of the verb are topic, which introduces a shift to an already known topic ('aboutness'), and focus, which presents new or surprising information or emphasis. Dahlstrom (2013) proposees a discourse-dependent clause structure with a functional structure to the right of the verb but no constituent structure. Rather, all nouns that have not moved to topic or focus position are in a flat XP structure to the right of the verb. Dahlstrom (2013) also states that the unmarked position for nominals is postverbal but that a basic order cannot be determined for the subject and object since both "VSO and VOS have an equal claim to being basic" (p. 8-1). Since word order is flexible and heavily influenced by discourse/information structure, identifying a basic word order can be difficult. While Meskwaki discourse-based word orders have been thoroughly investigated, the issue of a basic word order has not been addressed for various reasons, one being that much of the available data are structured texts with stylistic, discourse-based norms. Therefore, with limited context-free data for analysis, identifying a basic word order can be difficult. It has also been suggested that Meskwaki does not actually have a basic word order (Dahlstrom 1993, Goddard 2009).

Interestingly though, psycholinguistic studies have shown that language-specific basic word orders are used as a base for processing and producing discourse-based word orders (i.e., Sekerina 2003, Kaiser and Trueswell 2004, Erdocia, Laka, Mestres-Missé, and Rodriguez-Fornells 2009). To understand the significance of discourse-based word orders, speakers first process

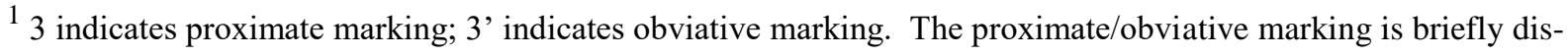
cussed below. For further discussion, see Thomason (2003).
} 
structures through a basic word order. Non-basic word orders increase processing time since word order is initially processed using a basic word order until later evidence, such as structural disambiguation from context, causes a listener to reanalyze the structure (Erdocia et al. 2009). The discourse status and prominence of information are analyzed based on variations from the basic word order of the language (Kaiser and Trueswell 2004). Data from event-related potentials (ERPs), measurements of electrical brain activity, also indicate increased syntactic processing when listeners hear non-basic word orders (Erdocia et al. 2009).

The surface characteristics of non-configurational languages have led to debates over the underlying syntactic structures that would allow for these characteristics. In general terms, two approaches have been posited to account for non-configurational characteristics (Hamilton 2013). One approach proposes that non-configurationality is represented in the underlying syntax of these languages. Unlike the rigid word order based on hierarchical relationships and ccommand in configurational languages, the underlying syntax of non-configurational languages is not based on structural relationships, which results in the free surface structure. The other approach proposes a hierarchical relationship between arguments in languages that show nonconfigurational characteristics, essentially that these languages are configurational, and that the surface structure found in these languages results from sources other than the underlying syntax. Under the non-configurational approach, it has been argued that there is no $\mathrm{VP}^{2}$ structure in Meskwaki and the syntactic structure of the language is flat (Dahlstrom 1993, Goddard 2009). However, recent work on non-configurational languages has argued that these languages are, in fact, configurational. In this paper, I propose that Meskwaki has an underlying configurational syntactic structure based on novel and prior data showing (1) discontinuous NP ordering restrictions with locality constraints, (2) superiority effects in multiple wh-phrases, and (3) longdistance movement and island effects.

2. Approaches to non-configurational characteristics. In this section, the approaches that have been proposed for analyzing non-configurational characteristics will be outlined. They have been grouped by how the underlying syntactic structure is analyzed.

2.1. NON-CONFIGURATIONAL APPROACHES. Non-configurational approaches provide differing analyses and accounts for free surface structure. The dual-structure approach proposed by Hale (1983) argues that syntax is divided into two structures, the phase structure (PS) and the lexical structure (LS). The lexical structure is hierarchical and includes phonological forms, lexical entries, and their categorical classifications, while the phrase structure layer represents the syntactic structures associated with case and argument position (Hale 1983). Lexical-Functional Grammar (LFG), another dual-structure approach, proposes that in head-marking languages, the only element in the c-structure is the verb. Overt nominal and pronominal representations are listed in

\footnotetext{
${ }^{2}$ The lack of weak crossover effects (WCO) has been taken as evidence against a verb phrase. Dahlstrom (1987) argues against a VP structure in Meskwaki based on weak crossover effects. In asymmetrical c-command structures, weak crossover constructions are ungrammatical because the c-command structure is violated through linear order. However, acceptable WCO structures are argued to show that there is a symmetrical relationship between the subject and object NPs (Dahlstrom 2013). However, Hamilton (2015) argues against WCO analyses due to the proximate/obviative marking system found in many Algonquian languages. Since only one 3rd person noun in a clause can be proximate, with all others being obviative, obviative nouns are obligatorily disjoint-referenced with proximate 3rd person nouns. Because of this, Algonquian languages do not actually show WCO effects (Brittain 2001). Thus, the lack of binding through word order in Meskwaki and other Algonquian languages does not necessarily indicate the lack of a VP.
} 
the lexicon (Dahlstrom 2013). Dual-structure approaches propose a flat syntactic structure, allowing for expressions to be base-generated in any position since there is no hierarchical structure, meaning that nouns are not generated in argument position. Under a flat structure analysis, objects are not constituents of verbs, and subjects and objects are in a sister relationship, resulting in no mutual c-command or structural asymmetries (Legate 2002). Since the syntactic structure is not hierarchical and lacks c-command relationships, it is also argued that there is no verb phrase structure (VP) in non-configurational languages.

Another non-configurational approach, the Pronominal Argument Hypothesis (PAH) (Jelinek 1984), proposes that the argument structure in non-configurational languages is based on morphology, allowing for pronominal arguments. The main claim of the PAH is that argument positions are satisfied by clitic pronouns, which are the true syntactic arguments, while nominals are adjuncts, which accounts for how non-configurational characteristics are licensed. Since overt nouns are adjuncts, they can appear in any position.

2.2. NON-CONFIGURATIONAL ACCOUNT OF MESKWAKI. Under a non-configurational approach, Meskwaki is analyzed as having a flat, non-hierarchical structure (Dahlstrom 1993, Goddard 2009) with no c-command relationships. However, quite a few restrictions on Meskwaki word order have been proposed. There is a slot in the $\mathrm{S}$ structure where focused overt NPs can move, creating a discourse-licensed structure (Dahlstrom 2013). Negation particles, focused nouns, obliques, and verbs exist in the $S$ structure in a linearized order (Dahlstrom 2013). Since some topics show properties of being clause-external while others show clause-internal properties, Dahlstrom (2004) proposes that topics are in the S' node above $S$ and in a sister relationship with S. Non-topicalized or focused subjects, objects, and compliments are in an XP structure to the right of the verb, as shown in Figure 1 (Dahlstrom 2013). Additionally, relative roots must follow their complements (Thomason 2003).

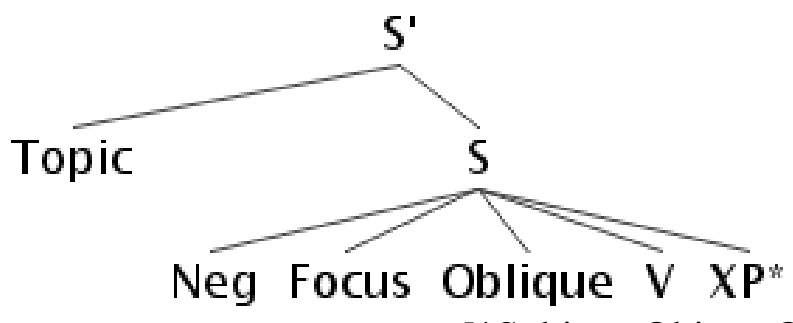

[*Subject, Object, Object 2, Complement]

Figure 1. Discourse-Configurational Structure of Meskwaki ${ }^{3}$

While there is not a clear consensus on the exact details between pre- and postverbal nominals, preverbal nominals are generally considered sharply focused or topicalized and postverbal nominals are defocused (Thomason 2004). However, as Sullivan (2012) states, this pre-/postverbal distinction does provide a reasonable account of the seemingly free word order in Algonquian languages, where verbal arguments are to the right of the verb unless there is a discourse-driven reason for them to appear, or move, to the left of the verb.

2.3. "HYBRID” ACCOUNT. In a revision of Pronominal Argument Hypothesis, Baker (1996) proposed a similar approach to overt nouns with argument structure expressed through agreement with verbal morphology or noun incorporation but with hierarchical A-positions in which null pronominals, $w h$-phrases, and complement clauses are base-generated. Since null pronominals

\footnotetext{
${ }^{3}$ Image from Dahlstrom (2013, p. 8-2).
} 
fill A-positions, overt nominals are adjuncts, so nouns representing subjects and objects never enter a c-command relationship. This approach accounts for both $w h$-movement and binding into complement clauses found in Mohawk, while also accounting for other non-configurational characteristics in the language. Hamilton (2015) refers to this as a "hybrid" approach.

However, Baker's (1996) approach makes stipulations on which languages can be considered polysynthetic, and therefore non-configurational, based on features they have or do not have. To be considered polysynthetic, a language must allow noun incorporation as a strategy for head-marking (Baker 1996). Additionally, languages that can optionally, but not obligatorily, mark all arguments on the head are not viewed as 'fully' polysynthetic (Baker 2001). Baker (1996) also argues against the existence of discontinuous constituents because of their limitations in Mohawk, involving only determiners and quantifiers and a final N' constituent. Baker (1996) claims that polysynthetic languages do not have true quantifier phrases but instead have quantificational adverbs.

However, languages other than Mohawk do have discontinuous constituent structures, which undermines the "hybrid" approach. Warlpiri, for example, does not have discontinuous restrictions, as discontinuous elements can appear in any order and can also be found in possessive constructions (Legate 2002). MacSwan (1998) makes a similar argument about quantifier phrases in Southeastern Puebla Nahuatl, which does have true quantifier phrases resulting from true quantifier loan words from Spanish. Furthermore, Bruening (2001) identifies 'all' as having a bound, true quantifier reading in Mohawk. Additionally, scope ambiguities are present in the polysynthetic Algonquian language Mi'gmaq, which is not expected under a "hybrid" account where quantifiers are base-generated as adjuncts.

2.4. CONFIGURATIONAL APPROACHES. Through the analysis of specific structural factors, multiple languages that were once considered non-configurational have been shown to exhibit evidence of an underlying configurational syntactic structure. Many languages, for example, have null anaphora (PRO-drop) but are not considered non-configurational, such as Spanish, Italian, and Chinese. Discontinuous constituent structures are also found in configurational languages, such as Slavic and Germanic languages (Legate 2002). Languages that allow variable word orders due to movement, either for discourse purposes, such as Hungarian, or scrambling, such as German and Japanese, and variable verb raising, such as Irish, were claimed to be nonconfigurational but have been shown to have configurational structures (Bruening 2001). These studies call into question the idea that the existence of a set of non-configurational features in a language implies a non-configurational structure (Haugen 2015). Several polysynthetic and dependent-marking languages considered to be non-configurational have been argued to show configurational features, such as Warlpiri (Legate 2002), Classical Nahuatl (Haugen 2015), Southeast Puebla Nahuatl (MacSwan 1998) and Algonquian languages including Mi'gmaq (Hamilton 2013, 2015), Passamaquoddy (Bruening 2001), Western Naskapi (Brittain 2001), and Proto-Algonquian (Oxford 2014).

Some arguments in favor of configurational approaches are based on word order analyses. In an analysis of Classical Nahuatl, Haugen (2015) argues that while OSV should be an acceptable word order due to the non-configurational characteristics of the language, it is "virtually" unattested which indicates that the language did not actually have free word order. Since SOV is possible, but not OSV, Haugen (2015) claims a locality constraint for topic and focus positions which prevents objects from moving past subjects in the left periphery. This restriction points to an asymmetric subject-object relationship based on a hierarchical structure (Haugen 2015). The language also shows evidence of subject movement based on vP-remnants and 
indefinite NPs are subject to obligatory movement when the vP is fronted (Haugen 2015). MacSwan (1998) also claims that word order is not free in Southeast Puebla Nahuatl and proposes an SVO order with preverbal object and postverbal subjects for focus. This claim is based on consultants stating that SVO order is the most natural and SOV and VSO acceptable for focus or contrast. OVS order was judged to be unacceptable. Textual analyses also indicate a statistical preference for SVO order (MacSwan 1998).

Evidence in support of a configurational approach also comes from multiple wh-question ordering. In Mi'gmaq, subject $w h$-phrases must appear before object $w h$-phrases. Hamilton (2015) argues that this is expected under a configuration account because $w h$-subjects and $w h$ objects are base-generated in A-position and the resulting c-command relationship must be maintained after $w h$-movement. In languages that have strict $w h$-ordering, subject $w h$-phrases must precede object wh-phrases due to superiority effects (Chomsky 1973, Richards 1997). This strict ordering is unexpected under non-configurational accounts.

Hamilton (2015) argues that patterns in Mi'gmaq Long-Distance Agreement also provide evidence in support of a configurational account. In Mi'gmaq, only subjects in direct structures and objects in inverse structures are permitted for Long-Distance Agreement with declarative embedded clauses; this subject-object asymmetry is argued to only be explicable under a configurational account (Hamilton 2015). Long-Distance Agreement is also found in MaliseetPassamaquoddy, an Eastern Algonquian language (Bruening 2001). In successive cyclic whmovement, agreement appears on all verbs in the path, indicating that successive cyclic $w h$ movement is dependent on agreement with movement operators. Wh-phrases must Agree with heads of phrases to move through them (Bruening 2001). Bruening (2001) also argues that elements in raising-to-object positions are not actually objects but are rather at the left-most edge of the phrase. This is because the raised element agrees with the higher verb but is restricted from moving out of the edge of the lower clause. This points to a configurational, hierarchical structure for the language despite non-configurational characteristics.

Besides evidence of movement from successive cyclic wh-movement found in MaliseetPassamaquoddy (Bruening 2001) and Mi'gmaq (Hamilton 2015) discussed above, further evidence of movement comes from island constraints found in Maliseet-Passamaquoddy (Bruening 2001), Mi'gmaq (Hamilton 2015), and Warlpiri (Legate 2002). This provides further evidence against free word orders and indicates that wh-phrases are base-generated in A-position and undergo movement unless movement is blocked by island effects, rather than being base-generated in surface position, which supports a hierarchical, configurational account of languages with non-configurational characteristics.

3. The noun phrase. In Meskwaki, NPs follow the order of determiner, quantifier, modifier, noun, relative clause (Dahlstrom 1987); violations are not acceptable (4):

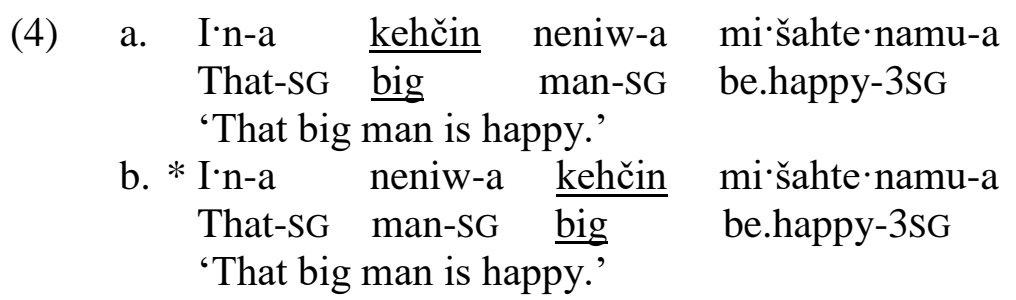

As Hamilton (2015) notes, the fact that only functional material can precede lexical material in discontinuous NPs in Meskwaki (Dahlstrom 1987) and other Algonquian languages is a counterargument against non-configurational approaches since there should not be any ordering 
restrictions if NPs can attach as adjuncts or appear in a flat structure in any order. Likewise, these ordering restrictions would not be expected under a "hybrid" approach such as Baker's (1996) since NPs are still considered adjuncts, as in the PAH, and would be predicted to be able to appear in any order. Furthermore, the fact that Meskwaki has discontinuous constituents is counterevidence against the "hybrid" approach as Baker (1996) stipulates that polysynthetic languages do not actually have discontinuous expressions. Meskwaki also shows discontinuous possessive constructions (Thomason 2005), which again is unexpected in a "hybrid" approach.

Unrelated nominals that intervene in quantified NPs, creating discontinuous NPs, cause unintended scope interpretations (5), showing that quantifiers look into their c-command for the closest available noun. This is accounted for if NPs are base-generated in A-positions and quantifiers then move, violating local binding (Hamilton 2013).

$$
\begin{array}{llll}
\text { a. Aneta neniw-aki ne'awew-aki } & \underline{\text { anemu-hani }} \\
\text { Some men-PL } & \text { 3PST-see-3 } & \underline{\text { dog-SG.OBV }} \\
\text { 'Some of the men saw the dog.' } & \\
\text { b. * Aneta } \underline{\text { anemu-hani }} & \text { neniw-aki } & \text { ne·awew-aki } \\
\text { Some } \underline{\text { dog-SG.OBV }} & \text { men-PL } & \text { 3PST-see-3 }
\end{array}
$$

Intended: 'Some of the men saw the dog.'

Literal: 'Some of the dog was seen by the men.'

If quantifiers are base-generated as adjuncts, as in "hybrid" or PAH accounts, scope ambiguities would be unexpected because there would not be a c-command relationship between the quantifier and noun that could be violated. However, if quantifiers are base-generated in argument positions along with the rest of the NP and then move, then scope ambiguities would be expected due to the binding relationship being violated by movement.

4. Multiple $w h$-phrases. Languages with multiple $w h$-questions either allow variable ordering or a strict subject>object wh-phrase order (Richards 1997). If there are ordering constraints between multiple wh-phrases, superiority effects would require that structurally higher phrases must precede the lower phrases (Chomsky 1973, Richards 1997). Superiority effects, which rely on configurational orders, stipulate that underlying subject-object c-command relationships must be maintained after the application of $w h$-movement. In languages where both $w h$-phrases move, their moved position will maintain the c-command relationship; in languages where only one $w h$ phrase moves, wh-movement can only apply to the one that is structurally higher (Chomsky 1973). If there are no superiority effects, as would be the case under a non-configurational account, then $w h$-phrases could appear in any order.

In Meskwaki, single wh-phrases in main clauses appear in front of the verb, at the beginning of the sentence. Multiple wh-phrases are acceptable in Meskwaki (6a.), though they are rare. Multiple wh-questions in Meskwaki adhere to the strict subject>object ordering (6a \& 6b).

$$
\begin{aligned}
& \begin{array}{l}
\text { a. wene ne'piata'k'wa } \\
\text { who } \quad \text { 3PST-bring.to.me-3 } \underline{\text { what }}
\end{array} \\
& \text { 'Who brought me what?' } \\
& \text { b. * wekone wene ne'piata'k'wa? } \\
& \text { what who 3PST-bring.to.me-3 } \\
& \text { 'Who brought me what?' } \\
& \text { c. *wene wekone ne'piata' } \mathrm{k} \text { 'wa? } \\
& \text { who what 3PST-bring.to.me-3 }
\end{aligned}
$$

'Who brought me what?' 
The fact that the subject and object $w h$-phrases have strict relative ordering indicates the need to maintain a c-command relationship. The subject-object $w h$-asymmetries can only be explained as phrases base-generated in A-position (Hamilton 2015). This ordering, as stated by (Hamilton 2015), is a superiority effect, indicative of a hierarchical structure. These $w h$-ordering restrictions are unexpected under a non-configurational approach.

It is also unacceptable to move an object $w h$-phrase left of the verb in a multiple $w h$ structure in Meskwaki (6c), indicating that object $w h$-phrases must remain in situ. This also indicates that $w h$-phrases are base-generated in A-position then move to the front of the structure, but when they are not targeted for movement, they are bound in their base position.

5. Movement. While movement from $w h$-islands is acceptable in Meskwaki (7) (Dahlstrom 2013), Roberts (1996) states that $w h$-island violations are often acceptable in many languages and are considered weaker than other island effects. However, (7) shows that the subordinate clause verb is inflected for the moved $w h$-phrase in the matrix clause (marked as proximate 3.SG on both verbs), which is indicative of long-distance movement from base-generated argument positions. In successive cyclic $w h$-movement, agreement appears on all verbs in the path, indicating that successive cyclic $w h$-movement is dependent on agreement with movement operators. Wh-phrases must Agree with heads of phrases to move through them (Bruening 2001).

$$
\begin{aligned}
& \text { [we·ne·ha]=ča·hi ne·na·toše'yana [owiye-hani e·ši-ne·wokokwe·ni]? } \\
& \text { Who =so ask-2/PART/3 [anyone-OBV thus-see 3'-3/INTER.PART/OBL] } \\
& \text { 'Who did you ask whether anyone saw } \emptyset_{\mathrm{i}} \text { ?' }
\end{aligned}
$$

(Dahlstrom 2013, p. 8-21)

5.1. AdJUNCT \& COMPLEX NP ISLANDS. Meskwaki shows adjunct (8) and NP (9) island effects. The restriction on moving tana out of the adjunct clause $(8 \mathrm{~b} \& 8 \mathrm{c})$ shows that adjunct and complement clauses are in different structural positions, evidence of a hierarchical structure and movement (Bruening 2001).
a. neniw-a akwese·tu-kweni
man-SG 3PST-pack-3SG.INAN
'The man packed a bag before going where?'
b. * [tana] neniw-a akwese·tu-kweni meši-kimute [ehpai penuči ]? [Where ${ }_{\mathrm{i}}$ ] man-SG 3PST-pack-3SG.INAN big-sack.INAN [before go $\varnothing_{\mathrm{i}}$ ] 'The man packed a bag before going where?'
c. * neniw-a akwese tu-kweni meši-kimute [tana ehpai penuči ]? man-SG 3PST-pack-3SG.INAN big-sack.INAN [where i $_{i}$ before go $\varnothing_{\mathrm{i}}$ ] 'The man packed a bag before going where?'

Island effects can further be seen in NP islands. Sentence (9a) shows a grammatically wellformed sentence with a complex NP island. When the wh-object phrase is moved out of the island in (9b), the sentence is deemed ungrammatical. This is because extraction from the clause requires movement through the phase. However, the phase boundary is blocked by an intervening NP: 

a. Jona ašema-kweni
anemu-hani [pemene-kata
wene-hani]?
John 3PST-feed-3'SG.OBV
dog-SG.OBV [chase-conj-3'sG.OBV
who-OBV]
'John fed the dog that chased who?'
b. *[wene-hani] Jona ašema-kweni [whoi-OBV] John 3PST-feed-3'sG.OBV
'John fed the dog that chased who?'
anemu-hani [pemene-kata
dog-SG.OBV [chase-conj-3'sG.OBV $\left.\emptyset_{\mathrm{i}}\right]$

The Adjunct and NP island effects shown here provide evidence that $w h$-phrases are base-generated in A-position but are blocked from movement because of island effects. Under a nonconfigurational approach, this would be unexpected because the $w h$-phrases would be able to appear in any position. Thus, the data presented here support a hierarchical, configurational account of Meskwaki.

6. Conclusion. While surface order expresses discourse-based information structure in Meskwaki, the restrictions outlined here provide evidence of an underlying configurational structure that is syntactically hierarchical. Discontinuous expressions in the NP show effects of scope and ordering restrictions, evidence against adjunct-generated accounts of non-configurationality, including "hybrid" accounts. Furthermore, the existence and behavior of multiple wh-questions and island effects are evidence of a hierarchical structure, as well as movement. The position of $w h$-object phrases and the restrictions of object $w h$-phrases to the right of the verb in islands are indicative of c-command relationships in a configurational analysis with objects arguments being base-generated to the right of the verb. The restrictions on $w h$-questions and the existence of island effects are unexpected under non-configurational approaches. Rather, the data presented here indicate that Meskwaki has a hierarchical, configurational syntactic structure despite the surface structure non-configurational characteristics.

\section{References}

Baker, Mark. 1996. The polysynthesis parameter. New York: Oxford University Press. Baker, Mark. 2001. The atoms of language. New York: Basic Books.

Bresnan, Joan. 1995. Linear order vs. syntactic rank: evidence from weak crossover. In Katharine Beals (Ed.), Papers from the thirtieth regional meeting of the Chicago Linguistics Society. 57-89. Chicago: University of Chicago.

Brittain, Julie. 2001. The morphosyntax of the Algonquian conjunct verb: A minimalist approach. New York: Garland Publishing.

Bruening, Benjamin. 2001. Syntax at the edge: cross-clausal phenomena and the syntax of Passamaquoddy. Cambridge, MA: Massachusetts Institute of Technology dissertation. http://hdl.handle.net/1721.1/8198.

Chomsky, Noam. 1973. Conditions on transformations. In S. Anderson \& P. Kiparsky (Eds.), $A$ festschrift for Morris Halle. 232-286. New York: Holt, Rinehart \& Winston.

Dahlstrom, Amy. 1987. Discontinuous constituents in Fox. In Paul D. Kroeber and Robert E. Moore (Eds.), Native American languages and grammatical typology. 53-73. Bloomington: Indiana University.

Dahlstrom, Amy. 1993. The syntax of discourse functions in Fox. In David A. Peterson (Ed.), Berkeley Linguistics Society 19. Special session on syntactic issues in Native American lan-guages. 11-21. Ann Arbor: Braun-Brumfield. https://doi.org/10.3765/bls.v19i2.1558.

Dahlstrom, Amy. 1995. Topic, focus, and other word order problems in Algonquian. The Belcourt Lecture. Winnipeg: Voices of Rupert's Land. 
Dahlstrom, Amy. 2003. Focus constructions in Meskwaki (Fox). In Miriam Butt and Tracy H. King (Eds.), Proceedings of the LFG03 Conference. 144-163. Stanford: CSLI Publications. http://web.stanford.edu/group/cslipublications/cslipublications/LFG/8/pdfs/lfg03dahlstrom.pdf.

Dahlstrom, Amy. 2013. Meskwaki syntax book. Manuscript in preparation. University of Chicago, Chicago, IL. https://lucian.uchicago.edu/blogs/adahlstrom/publications-2/ selected-manuscripts/meskwaki-syntax-book/.

Erdocia, Kepa, Itziar Laka, Anna Mestres-Missé \& Antoni Rodriguez-Fornells. 2009. Syntactic complexity and ambiguity resolution in a free word order language: behavioral and electrophysiological evidences from Basque. Brain and Language 109(1). 1-17. https://doi.org/10.1016/j.bandl.2008.12.003.

Goddard, Ives. 1978. Eastern Algonquian languages. In Bruce Trigger (Ed.), Handbook of North American Indians, Volume 15, Northeast. 70-77. Washington: Smithsonian Institution.

Goddard, Ives. 2009. Meskwaki (Algonquian) evidence against basic word order. Unpublished manuscript.

Hale, Ken. 1983. Warlpiri and the grammar of non-configurational languages. Natural Language \& Linguistic Theory 1(1). 5-47. http://www.jstor.org/stable/4047512.

Hamilton, Michael D. 2013. Against non-configurationality in Mi'gmaq. Presented at SSILA Annual Winter Meeting. Unpublished manuscript. http://migmaq.org/wpcontent/uploads/2013/10/SSILA.pdf.

Hamilton, Michael D. 2015. Phrase structure in Mi'gmaq: A configurational account of a "nonconfigurational" language. Lingua 167. 19-40. https://doi.org/10.1016/j.lingua.2015.07.003.

Haugen, Jason. D. 2015. Configurationality in Classical Nahuatl. In Emily Sadlier-Brown, Erin Guntly, and Natalie Weber (Eds.), Proceedings of the Workshop on Structure and Constituency in the Languages of the Americas 20. 56-70. Vancouver: University of British Columbia. http://ling.auf.net/lingbuzz/002453.

Jelinek, Eloise. 1984. Empty categories, case and configurationality. Natural Language \& Linguistic Theory 2(1). 39-76. https://www.jstor.org/stable/4047560

Kaiser, Elsi and John C. Trueswell. 2004. The role of discourse context in the processing of a flexible word-order language. Cognition 94(2). 113-147. https://doi.org/10.1016/j.cognition.2004.01.002.

Legate, Julie A. 2002. Warlpiri: Theoretical implications. Cambridge, MA: Massachusetts Institute of Technology dissertation. http://www.ling.upenn.edu/ jlegate/main.pdf

Nichols, Johanna. 1986. Head-marking and dependent-marking grammar. Language 62. 56-119. https://www.jstor.org/stable/415601.

MacSwan, Jeff. 1998. The argument status of NPs in Southeast Puebla Nahuatl: Comments on the polysynthesis parameter. Southwest Journal of Linguistics 17(2). 101-114.

Mahieu, Marc Antoine \& Nicole Tersis (Eds.). 2009. Variations on polysynthesis: the Eskaleut languages (Vol. 86). Amsterdam: John Benjamins Publishing.

Richards, Norvin. 1997. What moves where when in which language? Cambridge, MA: Massachusetts Institute of Technology dissertation. http://www.ai.mit.edu/projects/dm/theses/richards97.pdf.

Roberts, Ian. 1996. Comparative syntax. London: Edward Arnold.

Sekerina, Irina. 2003. Scrambling and processing: Dependencies, complexity and constraints. In Simin Karimi (Ed.), Scrambling and word order. 301-324. Malden, MA: Blackwell.

Sullivan, Michael. 2012. Making statements in Ojibwe: A survey of word order in spontaneous sentences. In Monica Macaulay, Margaret Noodin \& J. Randoph Valentine (Eds.), Papers 
of the 44th Annual Algonquian Conference. 329-348. Chicago: University of Chicago.

Thomason, Lucy. 2003. The proximate and obviative contrast in Meskwaki. Austin, TX: University of Texas dissertation. https://repositories.lib.utexas.edu/handle/2152/990.

Thomason, Lucy. 2005. Meskwaki prenouns. In H. C. Wolfart (ed.), Papers of the 36th Annual Algonquian Conference. Winnipeg: University of Manitoba. https://ojs.library.carleton.ca/index.php/ALGQP/article/download/368/272/0. 